\title{
Synthesis and Characterization of Perfluorooctanoic Acid Anionic Surfactant Doped Nanosize Polyaniline
}

\author{
B. Mahalakshmi, C. Vedhi* \\ Department of Chemistry, V.O. Chidambaram College, Thoothukudi, India \\ Email: ${ }^{*}$ cvedhi@rediffmail.com, ${ }^{*} \underline{c}$ vedhi23@gmail.com
}

Received 22 June 2014; revised 4 August 2014; accepted 25 August 2014

Copyright (C) 2014 by authors and Scientific Research Publishing Inc.

This work is licensed under the Creative Commons Attribution International License (CC BY). http://creativecommons.org/licenses/by/4.0/

(c) (i) Open Access

\section{Abstract}

Surfactant doped polyaniline was synthesized in the aqueous solution of aniline and anionic surfactant of perfluorooctanoic acid (PFO) by chemical synthesis using potassium peroxy disulphate as an oxidant by varying the aniline to surfactant ratio. The solubility of the chemically prepared surfactant doped polyaniline (PANI) was ascertained and it showed good solubility in dimethyl sulfoxide (DMSO), dimethylformamide (DMF), acetone, acetonitrile, ethanol, aceticacid, trichloroethylene, dichloromethane, tetrahydrofuran, ethylacetate, diethylether, toluene, chloroform and sparingly soluble in $n$-hexane and water. The prepared polymers were characterized by fourier transform infrared spectroscopy (FTIR), UV-visible, X-ray diffraction (XRD), cyclic voltammetric (CV), EIS and scanning electron microscopy (SEM). The analysis of UV-visible and FTIR showed that aniline has been polymerized to PANI in its conducting emeraldine form. FTIR spectra showed that the peaks at 1670,3315 and $1400 \mathrm{~cm}^{-1}$ corresponded to PFO. FTIR spectra showed that amine peak observed at $1593 \mathrm{~cm}^{-1}$ was shifted to lower wave number due to the interaction between PANI and the surfactant. SEM analysis showed that the variation in morphology of doped PANI was predominantly dependent on the concentration of the surfactant. Elemental analysis was done by energy dispersive spectroscopic (EDAX) which shows the presence of $C, N, O, S$ and $F$. XRD pattern showed that the formation of nanosized $(18 \mathrm{~nm})$ and crystalline polymer. CV studies of the synthesized polymer exhibited good adherent behavior on electrode surface. It exhibited three oxidation peaks at approximately $0.283 \mathrm{~V}, 0.541 \mathrm{~V}$ and $0.989 \mathrm{~V}$ and two reduction peaks at 0.1421 and 0.3854 V. Electrical conductivity of PFO doped PANI was studied by impedance spectroscopic method.

\section{Keywords}

Polyaniline, Perfluorooctanoic Acid, Cyclic Voltammetry, Morphology, Electrical Conductivity

\footnotetext{
${ }^{*}$ Corresponding author.
}

How to cite this paper: Mahalakshmi, B. and Vedhi, C. (2014) Synthesis and Characterization of Perfluorooctanoic Acid Anionic Surfactant Doped Nanosize Polyaniline. Open Journal of Synthesis Theory and Applications, 3, 57-68. 


\section{Introduction}

Conducting polymers have become a popular basic material for advanced applications such as rechargeable batteries [1], optical devices [2], membranes [3], sensors and biosensors [4] [5], electromagnetic interference (EMI) shielding [6], antistatic coatings [7], etc. Among the conducting polymers family, PANI has attracted considerable attention because of its unique electrical, optical and electro-optical properties and its numerous potential applications [8]. One of the key problems related to the potential applications of polyaniline is its processability. Processability is an important requirement in conducting polymers for their possible commercial use. Since most of the conducting polymers are not processable, much of the efforts made in this field have been directed towards circumventing this problem. To solve this problem, various approaches have been tried, including addition of side groups to the polymer backbone [9], grafting of polymers to a non-conducting polymer [10], direct polymerization of intractable polymers into the final desired shape, making a composite of blend of conducting polymers [11] [12] and copolymerization [13]. Better processability may be achieved either by the synthesis on PANI in nano-micro scale particle, which is easier to disperse in a polymer matrix or by using an appropriate emulsifier which enhances the optical and electrical properties of PANI. Polymeric stabilizers (surfactant) affect the polymerization condition, kinetics and also the final properties of the polymer [14] [15]. Surfactants used as additives during the polymerization of aniline to effect the locus polymerization by using the emulsion [16] [17] or inverse emulsion [18]-[20] pathways, and thus to modify the molecular and supermolecular structure of the resulting PANI, and to improve the properties of the PANI with respect to conductivity, stability, solubility in organic solvents and processability. Surfactants have important implications in wetting, formation of foams, etc., in addition to aggregation of surfactants at interfaces [21]. Polymeric nanostructures are formed on surfaces due to combination of interfacial, intra- and inter-molecular forces [22]. Surfactants affect the preparation of PANI in three ways: 1) the presence of surfactant micellar and aqueous phases, thus altering the locus and the course of polymerization [18] [23], 2) anionic surfactants may acting as counter ions for conducting-polymer polycations, and 3) the hydrophobic part of the surfactant molecules may adsorbing on the produced conducting polymers, a surfactant thus becoming a part of the resulting material.

Suspension polymerization of aniline in the presence of dodecylbenzenesulfonic acid (DBSA) with styrene-butadiene-styrene (SBS) and without SBS was carried out and results indicate that DBSA acts simultaneously as a surfactant (emulsifier) and as a dopant [24] [25]. Particle size and conductivity can be decreased by increasing the concentration of stabilizer [26] [27]. These are related to the mass of insulating stabilizer adsorbed. The size and type of the dopant (anion) affect the morphology, size and electrical conductivity of resulting polymers [28] [29]. The type and concentration of oxidant (dopant), type of protonic acids and additives affect the yield and electrical conductivity of polyaniline prepared chemically [30]. The polarity of the counter ion plays an important role in the conductivity as well as in the chemical properties. Conductivity increases which small counter ions are used [31]. The surfactants influence the physical properties (morphology, solubility) of the resultant polymer [32]. It has been reported that nanotubes of hydrophobic interiors were prepared by disassembling anionic micelles in the inner walls of positive charge bearing conjugated polymer [33]. It was also studied that supramolecular complexes involving nanoscopic amphiphilic assemblies (AAs) and polyelectrolytes have been used to prepare a variety of materials, wherein the dynamic AAs retain the structural features [34]. In this study, PANI-PFO was prepared in the aqueous solution by chemical oxidation method using KPS as an oxidant in the presence of various surfactant ratios. The effect of the anionic surfactant i.e., PFO on the chemical polymerization of aniline (An), at different surfactant ratios and potential windows is investigated. The doping of PFO changes the surface morphology of PANI. It is also found that electrical conductivity of PANI-PFO was better than that of PANI and governed by changing the concentration of surfactant during the polymerization of aniline.

\section{Experimental Section}

\subsection{Materials}

Perfluorooctanoic acid (PFO, surfactant) and potassium peroxydisulfate (KPS, oxidant) were purchased from merck AR grade and used as such without further purification. Aniline was purified by distillation in vacuum before use. 


\subsection{Synthesis of Polymer}

Aqueous micellar dispersion was prepared by chemical oxidation method. PFO doped PANI were synthesized by keeping the concentration of the monomer $(0.1 \mathrm{M})$ and oxidant $(0.1 \mathrm{M})$ constant and varying the molar ratio of PFO $\left(0.1 \mathrm{M}\right.$ to $\left.0.1 \times 10^{-5} \mathrm{M}\right)$. Table 1 describes the synthetic conditions of the respective samples. Bulk polymerization was carried out by mixing various molar ratio of surfactant into $2.3 \mathrm{ml}$ of $0.1 \mathrm{M}$ aniline and made up to $250 \mathrm{ml}$ using conductivity water. Polymerization was performed by the addition of potassium peroxydisulfate $(0.1 \mathrm{M})$ in the micellar solution and stirred for 5 hrs. The colour of polymerization solution changes with polymerization step. In the initial stage, aniline/PFO/APS solution was colorless with high transparency. As the polymerization proceeded, the color of the solution changes to white through yellow, brown and finally to green, which indicates the formation of PANI emeraldine salt (ES). The precipitated particles were collected after filtering and washing with distilled water and methanol several times to remove impurities such as KPS, free PFO and unreacted aniline. These particles were then dried at room temperature.

\subsection{Characterization}

FT-IR spectra (Model: SHIMADZU) of the polyaniline samples were recorded in the frequency range of 400 to $4000 \mathrm{~cm}^{-1}$. UV-Vis spectra of the samples in DMSO were taken using JASCO-V530 dual beam spectrophotometer in the wavelength region 200 to $1100 \mathrm{~nm}$ with a scanning speed of $400 \mathrm{~nm} / \mathrm{min}$. X-ray diffraction patterns of the polymers were obtained by employing XPERT-PRO diffractometer using $\mathrm{CuK}_{\alpha}\left(\mathrm{k}_{\alpha}=1.54060\right)$ radiation. The diffractometer was operated at $40 \mathrm{Kv}$ and $30 \mathrm{~mA}$. Powder X-ray diffraction pattern was recorded. The morphological study of the polymers were carried out using Scanning electron microscope (SEM Model: JEOL JSM 6360) operating at $25 \mathrm{kV}$. The electrochemical workstation (Model 650C), CH-Instrument Inc., TX, USA was employed for performing cyclic voltammmetry and impedance studies.

\section{Results and Discussion}

\subsection{UV-Vis Spectra}

Figure 1 shows the UV-visible spectra of PFO doped and undoped PANI. The band observed at $278 \mathrm{~nm}$ corresponds to $\pi-\pi^{*}$ transition. The absorption band at $373 \mathrm{~nm}$ was attributed to the $\pi-\pi^{*}$ transition within benzoid segment (excitation of the nitrogen atom in benzoid segment) and at $452 \mathrm{~nm}$ was related to the polaron band- $\pi^{*}$ transition of PANI (protonation in PANI backbone, polaron/bipolaron transition that occurred in doped PANI). A broad absorption band at $816 \mathrm{~nm}$ is assigned to the $\pi$-localised polaron bands of doped PANI in its emaraldine salt form (conductive emeraldine salt state of PANI) [35]-[38]. The band at around $373 \mathrm{~nm}$ is considerably blue shifted which indicates the interaction between PANI and the surfactant. The intensity of absorption band increases with the increasing PFO content. The shape of UV-Vis spectrum around $373 \mathrm{~nm}$ is changed from PANI 1 to PANI5 (Figures 1(a)-(e)). This suggests the change of doping characteristics.

\subsection{FTIR Spectra}

Figure 2 shows the infrared spectra of PFO doped and undoped PANI. The infrared peak at 1587 and $1496 \mathrm{~cm}^{-1}$ were assigned to the non-symmetric vibration mode of $\mathrm{C}=\mathrm{C}$ in quinoid and benzenoid ring system in polyaniline respectively. The peaks at 1297 and $1328 \mathrm{~cm}^{-1}$ were corresponds to the $\mathrm{C}-\mathrm{N}$ stretching vibration mode in

Table 1. Synthetic conditions of samples, molar concentration of aniline, PFO and KPS.

\begin{tabular}{cccc}
\hline Sample & Aniline (M) & KPS (M) & PFO (M) \\
PANI & 0.1 & 0.1 & $1 \times 10^{-1}$ \\
PANI 1 & 0.1 & 0.1 & $1 \times 10^{-2}$ \\
PANI 2 & 0.1 & 0.1 & $1 \times 10^{-3}$ \\
PANI 3 & 0.1 & 0.1 & $1 \times 10^{-4}$ \\
PANI 4 & 0.1 & 0.1 & $1 \times 10^{-5}$ \\
\hline
\end{tabular}




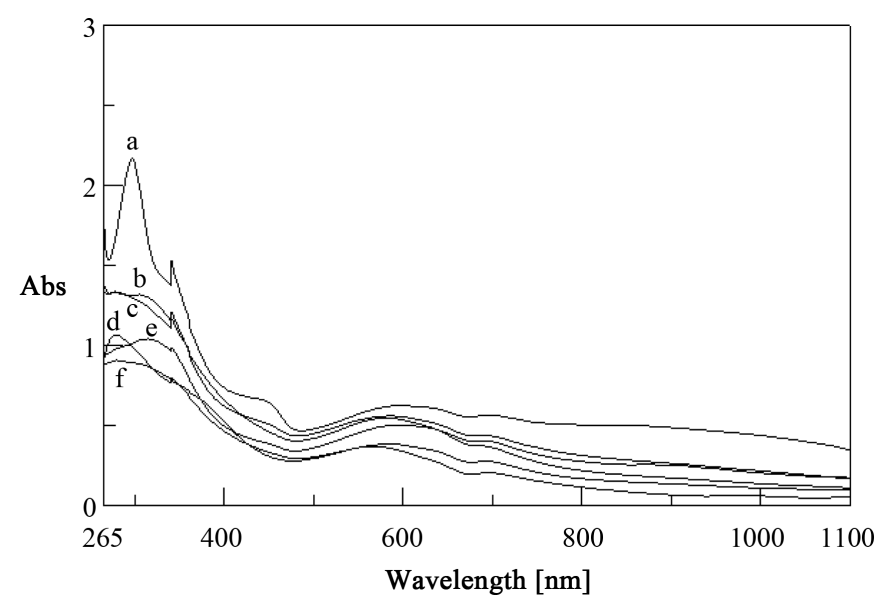

Figure 1. UV-spectra of (a) PANI 1; (b) PANI 2; (c) PANI 3; (d) PANI 4; (e) PANI 5; (f) PANI (undoped).

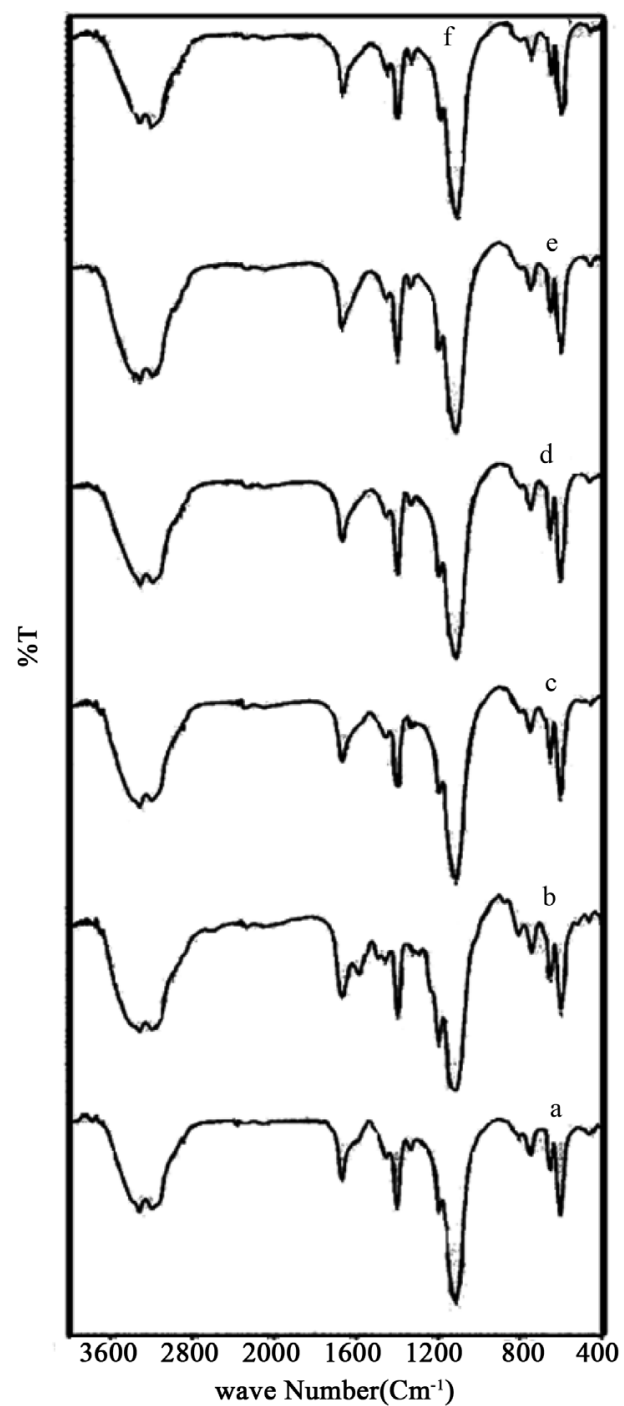

Figure 2. IR-spectra of (a) PANI (undoped); (b) PANI 1; (c) PANI 2; (d) PANI 3; (e) PANI4; (f) PANI 5. 
benzenoid and quinoid ring system of polyaniline assigned to conducted protonated form [36] [37]. The absorption band at $1116 \mathrm{~cm}^{-1}$ was assigned to in-plane vibration of $\mathrm{C}-\mathrm{H}$ bending vibration mode in $\mathrm{N}=\mathrm{Q}=\mathrm{N}, \mathrm{Q}-\mathrm{N}+$ $\mathrm{H}-\mathrm{B}$ or $\mathrm{B}-\mathrm{N}+\mathrm{H}-\mathrm{B}$ (where $\mathrm{Q}=$ quinoid and $\mathrm{B}$ = benzenoid). This absorption band should occur during the polymerization i.e., polar structure of the conducted protonated form. The absorption band at 882 and $816 \mathrm{~cm}^{-1}$ were attributed to the aromatic ring and out of plane $\mathrm{C}-\mathrm{H}$ deformation vibrations for 1,4-disubstituted aromatic ring system [39]. The band at $3195 \mathrm{~cm}^{-1}$ was assigned to C-H stretching vibrations of aromatic ring. The band at 1670, 3315 and $1400 \mathrm{~cm}^{-1}$ were corresponds to PFO. The relative intensity of these bands increases with increasing the surfactant content in the polymer. The amine vibration peak at $1593 \mathrm{~cm}^{-1}$ shifted to $1587 \mathrm{~cm}^{-1}$ due to the interaction between PANI and the surfactant. Hence FTIR shows surfactant well doped with the polymer.

\subsection{XRD Analysis}

Figure 3 shows the X-ray diffractograms of PFO doped and undoped PANI. XRD patterns provide information in relation to the nature and structure of the samples. XRD patterns of undoped sample of PANI shows the amorphous nature. XRD patterns of doped samples show the crystallinity. The conductivity of polymers depends on various parameters such as doping level, formation of polarons and bipolarons [40], the semi-crystalline nature of polymers arises owing to the systematic alignment of polymer chain folding or by the formation of single or multiple helices, for part of their length [41]. The pure PANI exhibited a broad hump at position $2 \theta=$ $21^{\circ}$ and $25^{\circ}$ as shown in the Figure 3(a). The PFO doped PANI exhibited sharp peak at $2 \theta=20^{\circ}$ and $26^{\circ}$, this indicated the presence of a high crystallinity and condensed structure. The intensity of the peak increases with increasing the concentration of the dopant. The nanosizes of the particles were confirmed by using DebyeScherrer's equation. The particle size varied gradually from $18 \mathrm{~nm}$ in the case of PANI 1 to $77 \mathrm{~nm}$ in the case of

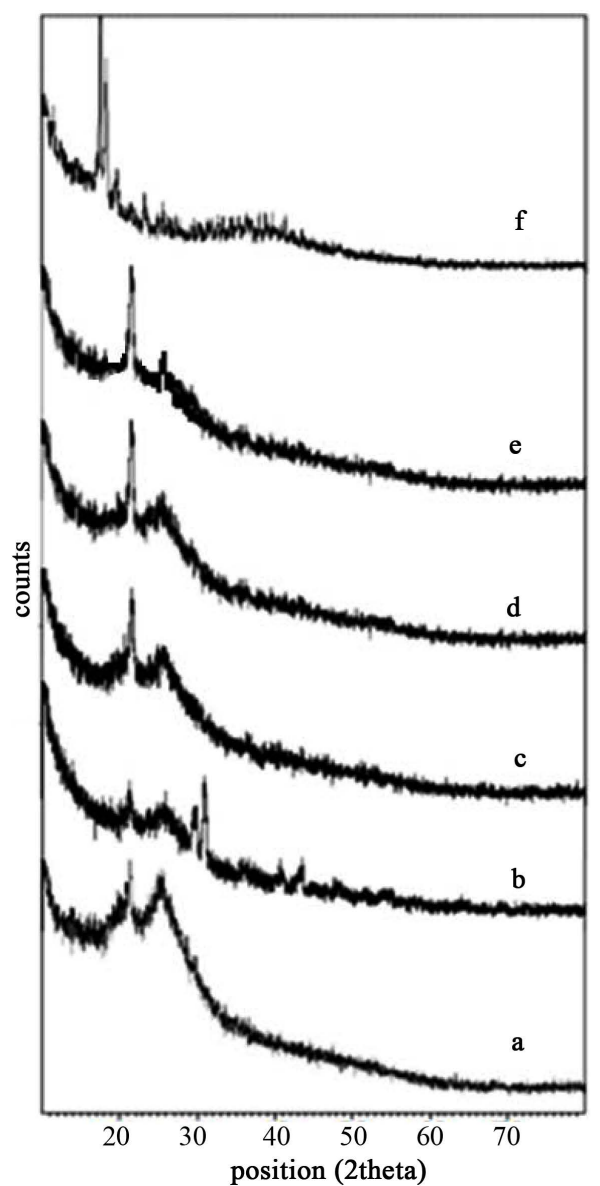

Figure 3. XRD scattering patterns of (a) PANI (undoped); (b) PANI 5; (c) PANI 4; (d) PANI 3; (e) PANI 2; (f) PANI 1. 
PANI 5 indicating that the concentration of the surfactant was highly influenced on the size of the particles. Particle size and conductivity can be decreased by increasing the concentration of stabilizer [26] [27]. The variation in diffraction intensity with dopant concentration exhibits with the interaction of PFO in PANI network.

\subsection{SEM Analysis}

The particle size and surface morphology were dependent on the type and concentration of surfactant, because the surfactant was adsorbed physically to the growing polymer [42]. Particle size decreases by increasing concentration of surfactant, because surfactant prevented from gross aggregation of particles. Figure 4 shows the surface morphology of doped and undoped PANI. However Figures 4(a)-(f) demonstrates the dependence of the size and homogeneity of the particles only from concentration of surfactant. Adsorption of the surface active agent on the PANI was primarily due to the hydrophobic component in the surfactant, probably via a hydrogen bonding mechanism with the aniline N-H group (graft copolymer) [27]. SEM photograph of the doped PANI show a gradual change from uneven flower like structure in PANI1 to a cage like morphology having more porous in PANI 5. The variation in morphology of the doped PANI was predominantly dependent on the concentration of the surfactant. Figure 5 Shows the EDS spectroscopy for the undoped and PFO doped PANI. It can be seen from a line that for the undoped PANI, only peaks corresponding to $\mathrm{C}, \mathrm{S}, \mathrm{O}$ and $\mathrm{N}$ elements were displayed. While for the PFO doped PANI, besides above peaks, peaks corresponding to C, O, S, N and F were also clearly observed, suggesting that $\mathrm{F}$ element originated from PFO was doped into the polymer.
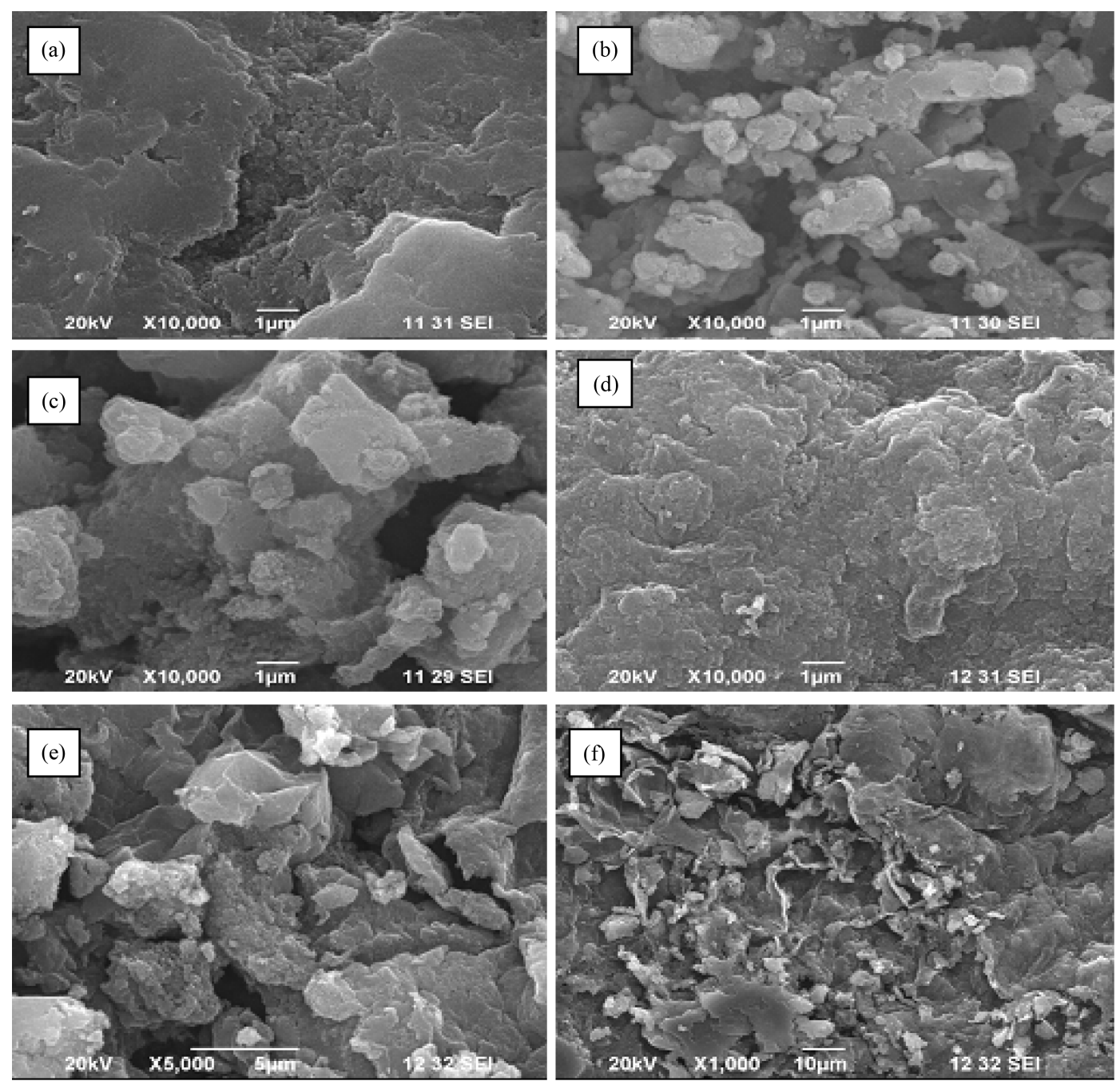

Figure 4. SEM images of (a) PANI (undoped); (b) PI 3; (c) PANI 2; (d) PANI 5; (e) PANI 4; (f) PANANI 1. 


\subsection{Cyclic Voltammogram}

Electrochemical behavior of undoped PANI and PFO doped PANI were shown in Figure 6. Cyclic voltammograms were recorded at room temperature by employing a three-electrode cell with platinum wire as an auxiliary electrode, as Ag/AgCl electrode as the reference electrode and coated glassy carbon (GC) as the working electrode. The CVs were obtained in $0.1 \mathrm{M} \mathrm{H}_{2} \mathrm{SO}_{4}$ by casting the polymer on GC working electrode and scanned

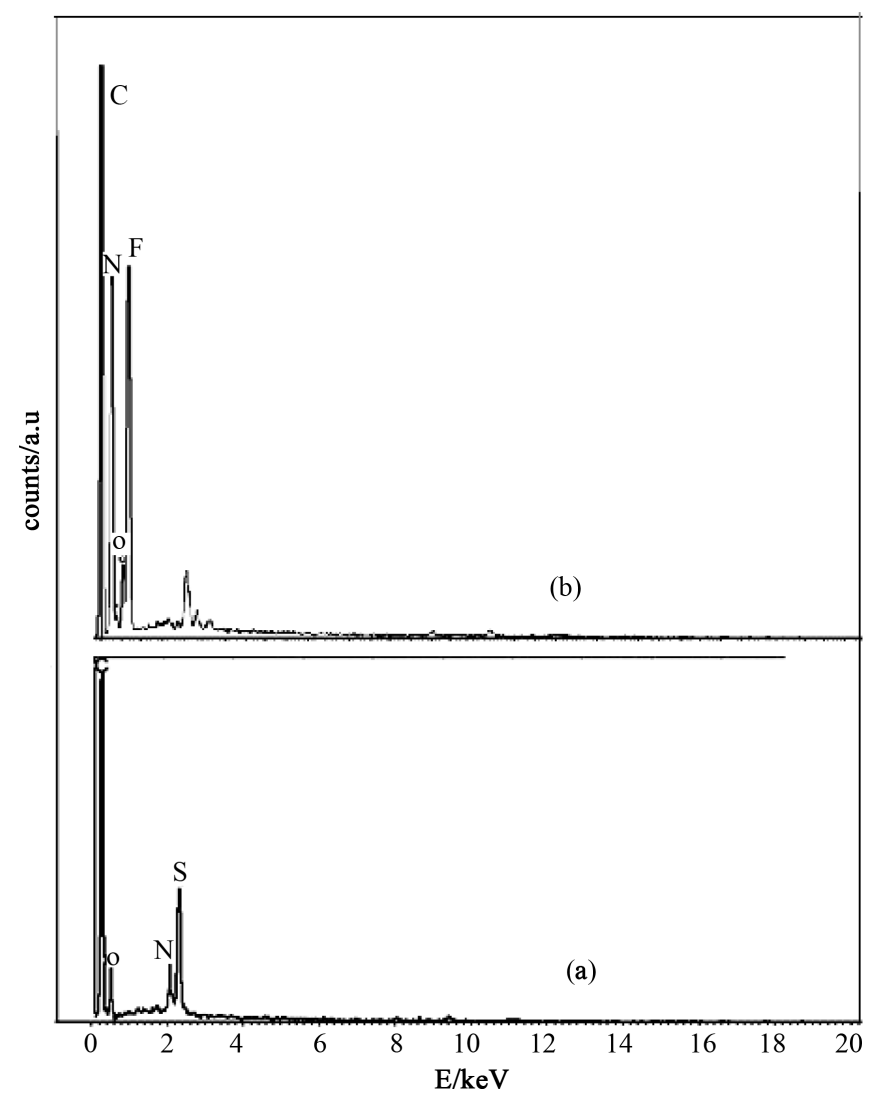

Figure 5. EDAX images of (a) PANI (undoped); (b) PANI 1.

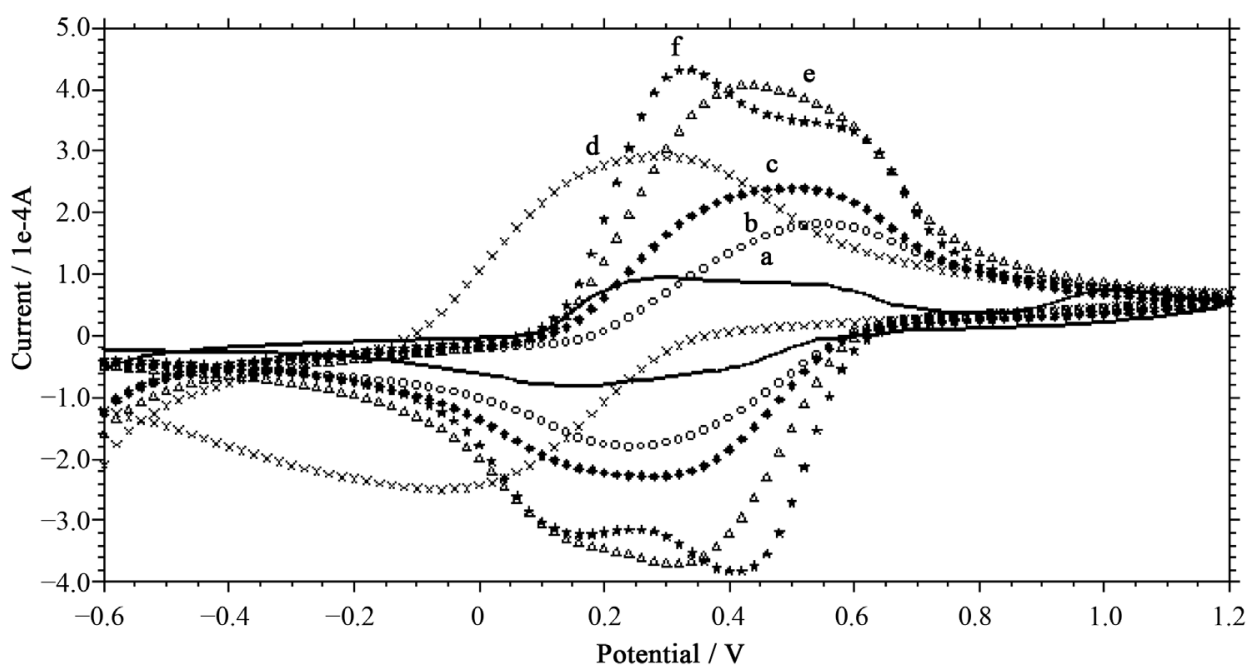

Figure 6. Cyclic voltammogram of (a) PANI (undoped); (b) PANI 5; (c) PANI 4; (d) PANI 3; (e) PANI 2; (f) PANI 1. 
between -0.6 to $1.2 \mathrm{~V}$ at scan rates between 25 and $500 \mathrm{mV} / \mathrm{s}$. The redox couple peak occurred at approximately $+283 \mathrm{mV}$ was attributed to the transformation of PANI from the reduced leucoemeraldine (LE) state to the partially oxidized emeraldine state (ES). The redox couple peak at approximately $+989 \mathrm{mV}$ corresponds to transition of the PANI from LE to pernigraniline (PE) state, and was accompanied by the oxidation of aniline monomer [43]. The redox couple peak at approximately $+541 \mathrm{mV}$, which was generally attributed to the redox reaction of p-benzoquinone [44]. The cathodic and anodic peak positions of PFO doped PANI shifted and increases the charge transfer with increasing the concentration of the surfactant were shown in the curve from (b-f). This increase in current was due to fast redox process at PANI-PFO matrix surface. The effect of varying scan rate ranges between $25 \mathrm{mV} / \mathrm{s}$ and $500 \mathrm{mV} / \mathrm{s}$ was studied at the PFO doped PANI in $0.1 \mathrm{M} \mathrm{H}_{2} \mathrm{SO}_{4}$ as shown in Figure 7 (a). With an increasing scan rate the peak current also increased thus indicating good adherence of the polymer onto the GC electrode surface, the peak current separation increased, and also the peak potential shifted slightly

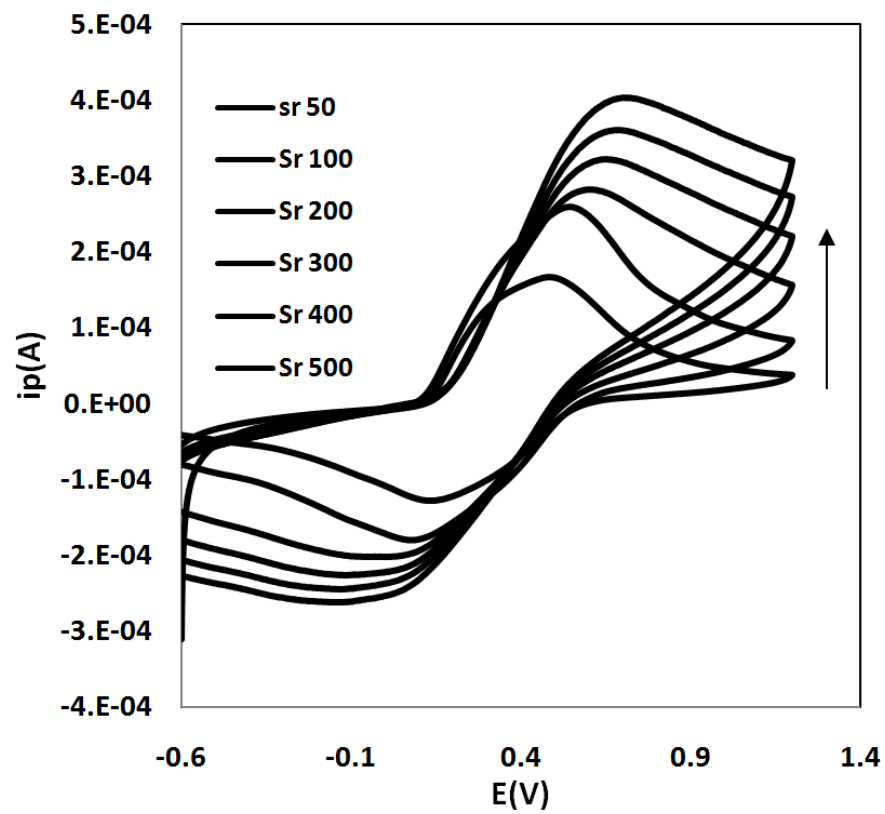

(a)

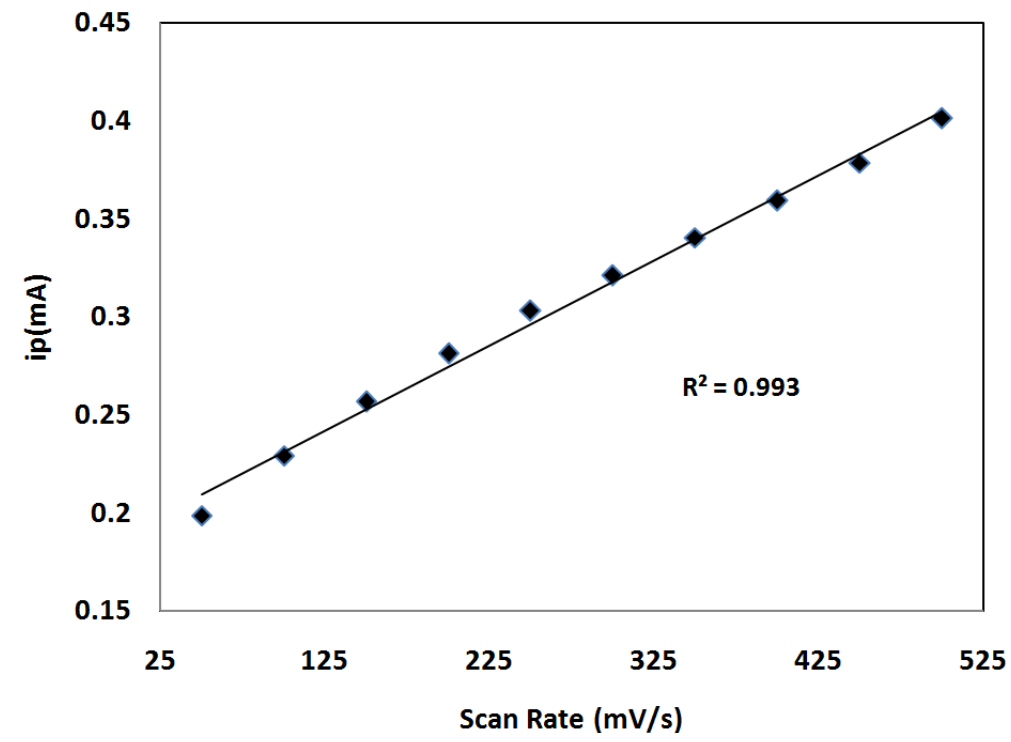

(b)

Figure 7. (a) CV taken at various scan rates for POT doped PANI; (b) A plot of anodic current against scan rate for POT doped PANI. 
with the anodic peak to positive and the cathodic peak to negative potential directions. This is because the charging and discharging of the electro-active conducting polymer is rate determining. As the scan rate increases the peak current of PFO doped polymer increased linearly, it is indicating an adherent film on the glassy carbon electrode, this was further confirmed by a straight line graph obtained by plotting peak current vs. scan rate as presented in Figure 7(b).

\subsection{Impedance Spectroscopy}

Figure 8 shows the typical Nyquist plots of PFO doped and undoped PANI in $0.1 \mathrm{M} \mathrm{H}_{2} \mathrm{SO}_{4}$. Electrochemical impedance spectroscopy was employed to obtain equivalent circuit parameters such as the charge transfer resistance and ohmic resistance. The impedance plots show a distorted semi-circle in the high-frequency region due to porosity of electrode and a vertically linear spike in the low-frequency region. The diameter of the semi-circle gives an approximate value of the charge transfer resistance (Rct) of the PANI/electrolyte interface. The charge transfer resistances (Rct) for PANI (undoped), PANI 1, PANI 2, PANI 3, PANI 4 and PANI 5 were estimated to be around 1116, 843, 658, 437, 382 and $320 \Omega$ respectively. The radii of the semicircle was found to increase with increase in surfactant concentration which indicates greater resistance to conduction with increase in PFO concentration which may result from more surfactant molecules bound to the electrode surface blocking the electron transfer. Thus PANI 5 with minimum PFO doping gives maximum conductivity.

\section{Conclusion}

Nano-sized PANI-PFO particles were prepared by chemical oxidation method with anionic surfactant. It had been found that the different concentration of surfactant had a considerable effect on the particle size and morphology of the resulting product. Better results were obtained for smaller concentration (PANI 5) of PFO. UV-Vis and FT-IR spectroscopy confirmed the interaction of PFO in PANI matrices. The SEM images show that the incorporation of PFO in PANI matrices changes the surface morphology of PANI. The chemical composition of polymer was further confirmed by EDAX analysis. XRD results show that the high concentration of surfactant exhibits the particle size of $18 \mathrm{~nm}$ and at low concentration of surfactant it exhibits the particle size of $77 \mathrm{~nm}$. PFO in PANI had enhanced charge transfer and current voltage characteristics at electrode interface which was studied by cyclic voltammogram. Increases in oxidation peak current and enhanced broadening were observed due to fast redox process in PANI-PFO matrix. It shows a linear relationship between anodic peak currents versus scan rate and it indicates that the polymer has an appropriate electro activity. Electrical conductivity can be decreased by increasing the concentration of PFO. Minimum PFO doped PANI shows maximum conductivity, and it is confirmed by impedance spectroscopic method. The change in surface morphology and

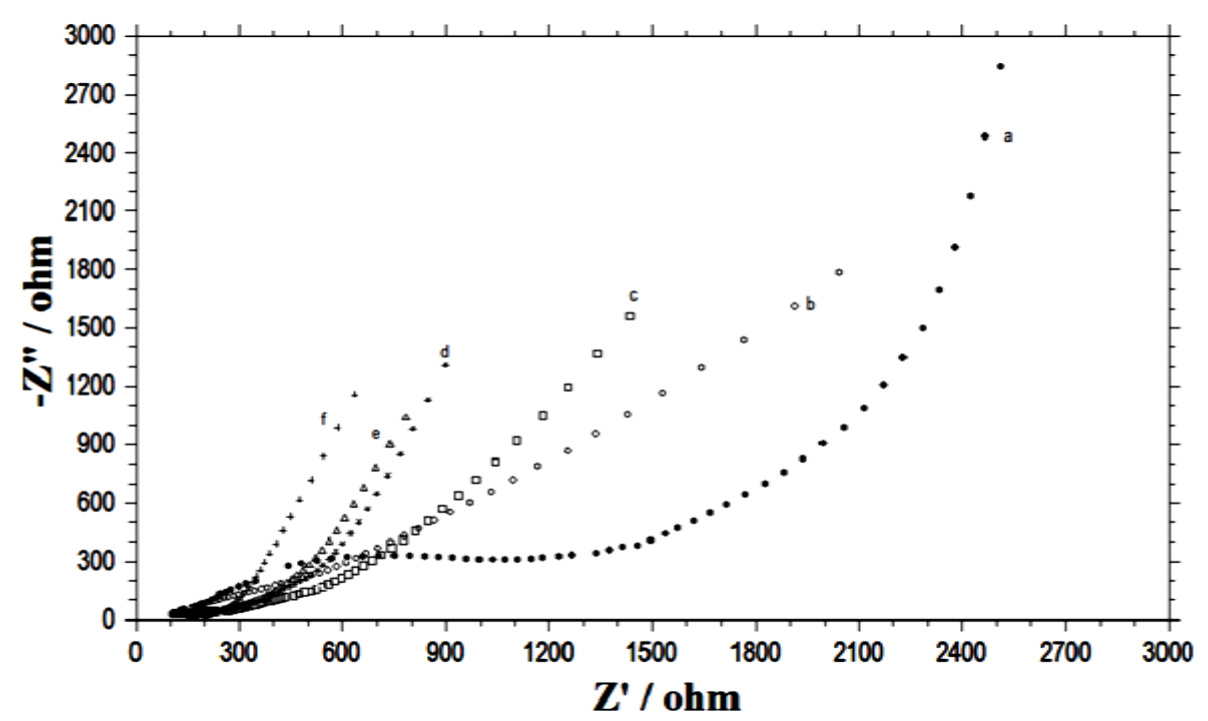

Figure 8. Nyquist plots for (a) PANI (undoped); (b) PANI 1; (c) PANI 2; (d) PANI 3; (e) PANI 4; (f) PANI 5. 
electrical conductivity of PANI-PFO with different concentrations of PFO show the potential for sensing application.

\section{Acknowledgements}

The authors are extremely grateful to DST (FAST TRACK and FIST) New Delhi, INDIA for using CHI Electrochemical workstation and Jasco UV-Vis Spectrophotometer.

\section{References}

[1] Scrosati, B. (1998) Conducting Polymers: Advanced Materials for New Design Rechargeable Lithium Batteries. Polymer International, 47, 50-55. http://dx.doi.org/10.1002/(SICI)1097-0126(199809)47:1<50::AID-PI4>3.0.CO;2-8

[2] Falcao, E.H.L. and De Azevedo, W.M. (2002) Polyanilinepolyvinyl Alcohol Composite as an Optical Recording Material. Synthetic Metals, 128, 149-154. http://dx.doi.org/10.1016/S0379-6779(01)00659-2

[3] Misoska, V., Ding, J., Davey, J.M., Price, W.E., Ralph, S.F. and Wallace, G.G. (2001) Polypyrrole Membranes Containing Chelating Ligands: Synthesis, Characterisation and Transport studies. Polymer, 42, 8571-8579.

http://dx.doi.org/10.1016/S0032-3861(01)00436-0

[4] Guernion, N., Ewen, R.J., Pihlainen, K., Ratcliffe, N.M. and Teare, G.C. (2002) The Fabrication and Characterisation of a Highly Sensitive Polypyrrole Sensor and Its Electrical Responses to Amines of Differing Basicity at High Humidities. Synthetic Metals, 126, 301-310. http://dx.doi.org/10.1016/S0379-6779(01)00572-0

[5] Yamato, H., Koshiba, T., Ohwa, M., Wernet, W. and Matsumura, M. (1997) A New Method for Dispersing Palladium Microparticles in Conducting Polymer Films and Its Application to Biosensors. Synthetic Metals, 87, 231-236. http://dx.doi.org/10.1016/S0379-6779(97)80114-2

[6] Dhawan, S.K., Singh, N. and Venkatachala, S. (2002) Shielding Behaviour of Conducting Polymer-Coated Fabrics in X-Band, W-Band and Radio Frequency Range. Synthetic Metals, 129, 261-267. http://dx.doi.org/10.1016/S0379-6779(02)00079-6

[7] Ohtani, A., Abe, M., Ezoe, M., Doi, T., Miyata, T. and Miyke, A. (1993) Synthesis and Properties of High-MolecularWeight Soluble Polyaniline and Its Application to the 4MB-Capacity Barium Ferrite Floppy Disks Antistatic Coating. Synthetic Metals, 57, 3696-3701. http://dx.doi.org/10.1016/0379-6779(93)90499-M

[8] Salanek, W.R., Lundstrom, I., Huang, W.S. and MacDiarmid, A.G. (1986) A Two-Dimensional Surfacestate Diagram for Polyaniline. Synthetic Metals, 13, 291-297. http://dx.doi.org/10.1016/0379-6779(86)90190-6

[9] Pandey, S.S., Annapoorni, S. and Malhotra, B.D. (1993) Synthesis and Characterization of Poly(aniline-co-o-anisidine). Macromolecules, 26, 3190-3193. http://dx.doi.org/10.1021/ma00064a032

[10] Andreatta, A., Heeger, A.J. and Smith, P. (1990) Electrically Conductive Poly Belend Fibers of Polyaniline and Poly(p-phenylene Terephthalamide). Polymer Communications, 31, 275-295.

[11] Nazzal, A.I. and Street, G.B. (1985) Pyrrole-Styrene Graft Copolymers. Journal of Chemical Society, Chemical Communications, 6, 375-376. http://dx.doi.org/10.1039/c39850000375

[12] Aldissi, M. (1984) Polyacetylene Block Copolymers. Synthetic Metals, 13, 87-100.

[13] Nalwa, H.S. (1990) Ferroelectric Polymers: Chemistry. Journal of Physics D: Applied Physics, 23, 745-748. http://dx.doi.org/10.1088/0022-3727/23/6/019

[14] Armes, S.P. and Aldissi, M. (1989) Novel Colloidal Dispersons of Polyaniline. Journal of Chemical Society, Chemical Communications, 2, 88-89. http://dx.doi.org/10.1039/c39890000088

[15] Kohut-Svelko, N., Reynaud, S. and Francois, J. (2005) Synthesis and Characterization of Polyaniline Prepared in the Presence of Nonionic Surfactants in an Aqueous Dispersion. Synthetic Metals, 150, 107-114. http://dx.doi.org/10.1016/j.synthmet.2004.12.022

[16] Kinlen, P.J., Liu, J., Ding, Y., Graham, C.R. and Remsen, E.E. (1998) Emulsion Polymerization Process for Organically Soluble and Electrically Conducting Polyaniline. Macromolecules, 31, 1735-1744.

http://dx.doi.org/10.1021/ma9714301

[17] Palaniappan, S. (2002) Preparation of Polyaniline-Sulfate Salt by Emulsion and Aqueous-Polymerization Pathway without Using-Protonic Acid. Polymers for Advanced Technologies, 13, 54-59. http://dx.doi.org/10.1002/pat.154

[18] Xia, H. and Wang, Q. (2001) Synthesis and Characterization of Conductive Polyaniline Nanoparticles through Ultrasonic Assisted Inverse Microemulsion Polymerization. Journal of Nanoparticle Research, 3, 399-409. http://dx.doi.org/10.1023/A:1012564814745

[19] Rao, P.S., Subrahmanya, S. and Sathyanarayana, D.N. (2002) Inverse Emulsion Polymerization: A New Route for the Synthesis of Conducting Polyaniline. Synthetic Metals, 128, 311-316. 
http://dx.doi.org/10.1016/S0379-6779(02)00016-4

[20] Rao, P.S., Sathyanarayana, D.N. and Palaniappan, S. (2002) Polymerization of Aniline in an Organic Peroxide System by the Inverted Emulsion Process. Macromolecules, 35, 4988-4996. http://dx.doi.org/10.1021/ma0114638

[21] Andrew, D.W.C., Rear, E.A.O. and Grady, B.P. (2003) Adsorbed Surfactants as Templates for the Synthesis of Morphologically Controlled Polyaniline and Polypyrrole Nanostructures on Flat Surfaces: From Spheres to Wires to Flat Films. Journal of the American Chemical Society, 125, 14793-14800. http://dx.doi.org/10.1021/ja0365983

[22] Rabe, J.P. (1998) Self-Assembly of Single Macromolecules at Surfaces. Current Opinion in Colloid and Interface Science, 3, 27-31. http://dx.doi.org/10.1016/S1359-0294(98)80038-1

[23] Ichinohe, D., Aria, T. and Kise, H. (1997) Synthesis of Soluble Polyaniline in Reversed Micellar Systems. Synthetic Metals, 84, 75-76. http://dx.doi.org/10.1016/S0379-6779(96)03843-X

[24] Xei, H.Q., Ma, Y.M. and Guo, J.S. (1998) Conductive Polyaniline-SBS Composites from in Situ Emulsion Polymerization. Polymer, 40, 261-265.

[25] Osterholm, J.E., Cao, Y., Klavetter, F. and Smith, P. (1994) Emulsion Polymerization of Aniline. Polymer, 35, 29022906. http://dx.doi.org/10.1016/0032-3861(94)90329-8

[26] Armes, S.P., Miller, J.F. and Vincent, B. (1987) Aqueous Dispersions of Electrically Conducting Monodisperse Polypyrrole Particles. Journal of Colloid and Interface Science, 118, 410-416. http://dx.doi.org/10.1016/0021-9797(87)90476-0

[27] Armes, S.P. and Aldissi, M. (1990) Preparation and Characterization of Colloidal Dispersions of Polypyrrole Using Poly(2-vinyl pyridine)-Based Steric Stabilizers. Polymer, 31, 569-574. http://dx.doi.org/10.1016/0032-3861(90)90404-M

[28] Hayashi, S., Takeda, S., Kaneto, K., Yoshino, K. and Matsuyama, T. (1987) Radiation Induced Effect in Conducting Polymers. Synthetic Metals, 18, 591-596. http://dx.doi.org/10.1016/0379-6779(87)90945-3

[29] Tang, M., Wen, T.Y., Du, T.B. and Chen, Y.P. (2003) Synthesis of Electrically Conductive Polypyrrole-Polystyrene Composites Using Supercritical Carbon Dioxide I. Effects of the Blending Conditions. European Polymer Journal, 39, 143-149. http://dx.doi.org/10.1016/S0014-3057(02)00167-2

[30] Cao, Y., Andreatta, A., Heeger, A.J. and Smith, P. (1989) Influence of Chemical Polymerization Conditions on the Properties of Polyaniline. Polymer, 30, 2305-2311. http://dx.doi.org/10.1016/0032-3861(89)90266-8

[31] Myers, R.E. (1986) Chemical Oxidative Polymerization as a Synthetic Route to Electrically Conducting Polypyrroles. Journal of Electronic Materials, 15, 61-69. http://dx.doi.org/10.1007/BF02649904

[32] Sun, B., Jones, J.J., Burford, R.P. and Skyllas-Kazacos, M. (1989) Stability and Mechanical Properties of Electrochemically Prepared Conducting Polypyrrole Films. Journal of Materials Science, 24, 4024-4029. http://dx.doi.org/10.1007/BF01168967

[33] Dutta, K., Mahale, R.Y., Arulkashmir, A. and Krishnamoorthy, K. (2012) Reversible Assembly and Disassembly of Micelles by a Polymer that Switches between Hydrophilic and Hydrophobic Wettings. Langmuir, 28, 10097-10104. http://dx.doi.org/10.1021/la301760a

[34] Das, C. and Krishnamoorthy, K. (2014) Disassembly of Micelles in Nanoscopic Space to Prepare Concentric Nanotubes with Variable Hydrophobic Interiors. Chemical Communications, 50, 5905-5908. http://dx.doi.org/10.1039/c4cc00841c

[35] Khan, R. and Dhayal, M. (2009) Chitosan/Polyaniline Hybrid Conducting Biopolymer Base Impedimetric Immunosensor to Detect Ochratoxin-A. Biosensors and Bioelectronics, 24, 1700-1705. http://dx.doi.org/10.1016/j.bios.2008.08.046

[36] Ansari, A.A., Khan, R., Sood, K.N. and Malhotra, B.D. (2009) Polyaniline-Cerium Oxide Nanocomposite for Hydrogen Peroxide Sensor. Journal of Nanoscience and Nanotechnology, 9, 4679-4685. http://dx.doi.org/10.1166/jnn.2009.1085

[37] Kaushik, A., Khan, R., Gupta, V., Malhotra, B.D. and Singh, S.P. (2009) Hybrid Cross Linked Polyaniline-WO 3 Nanocomposite Thin Films for $\mathrm{NO}_{\mathrm{x}}$ Gas Sensing. Journal of Nanoscience \& Nanotechnology, 9, 1792-1796. http://dx.doi.org/10.1166/jnn.2009.417

[38] Kaushik, A., Kumar, J., Tiwari, M.K., Khan, R., Malhotra, B.D., Gupta, V. and Singh, S.P. (2008) Fabrication and Characterization of Polyaniline-ZnO Hybrid Nanocomposite Thin Films. Journal of Nanoscience \& Nanotechnology, 8, 1757-1761. http://dx.doi.org/10.1166/jnn.2008.006

[39] Khan, R. (2011) Supported TritonX-100 Polyaniline Nano-Porous Electrically Active Film onto Indium-Tin-Oxide Probe for Sensors Application. Advances in Chemical Engineering and Science, 1, 140-146. http://dx.doi.org/10.4236/aces.2011.13021

[40] Fink, J. and Leising, G. (1986) Momentum-Dependent Dielectric Functions of Oriented Trans-Polyacetylene. Physical 
Review B, 34, 5320-5322. http://dx.doi.org/10.1103/PhysRevB.34.5320

[41] Kazim, S., Ali, V., Zulfequar, M., Haque, M. and Husain, M. (2006) Electrical, Thermal and Spectroscopic Studies of Te Doped Polyaniline. Current Applied Physics, 7, 68-75. http://dx.doi.org/10.1016/j.cap.2005.11.072

[42] Aldissi, M. and Armes, S.P. (1991) Colloidal Dispersion of Conducting Polymers. Progress in Organic Coatings, 19, 21-58. http://dx.doi.org/10.1016/0033-0655(91)80009-8

[43] Prasad, K.R. and Munichandraiah, N. (2001) Potentiodynamic Deposition of Polyaniline on Non-Platinum Metals and Characterization. Synthetic Metals, 123, 459-468. http://dx.doi.org/10.1016/S0379-6779(01)00334-4

[44] Cooper, J.C. and Hall, E.A.H. (1992) Electrochemical Response of an Enzyme-Loaded Polyaniline Film. Biosensors \& Bioelectronics, 7, 473-485. http://dx.doi.org/10.1016/0956-5663(92)80004-U 
Scientific Research Publishing (SCIRP) is one of the largest Open Access journal publishers. It is currently publishing more than 200 open access, online, peer-reviewed journals covering a wide range of academic disciplines. SCIRP serves the worldwide academic communities and contributes to the progress and application of science with its publication.

Other selected journals from SCIRP are listed as below. Submit your manuscript to us via either submit@scirp.org or Online Submission Portal.
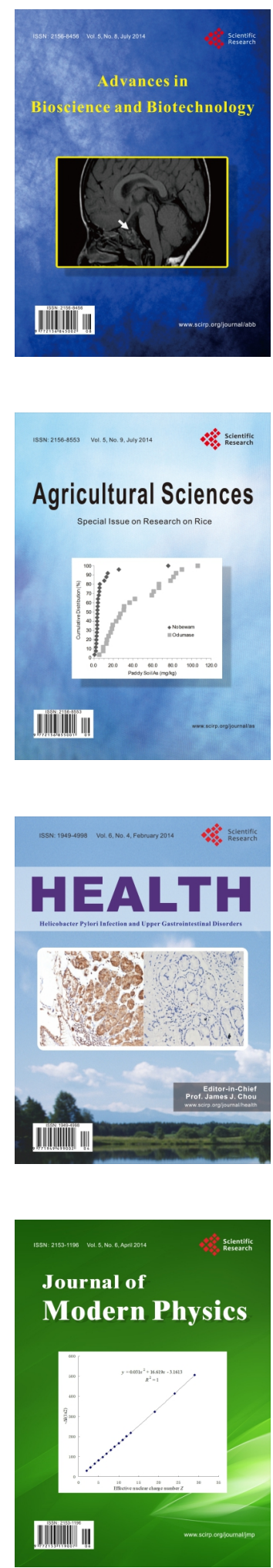
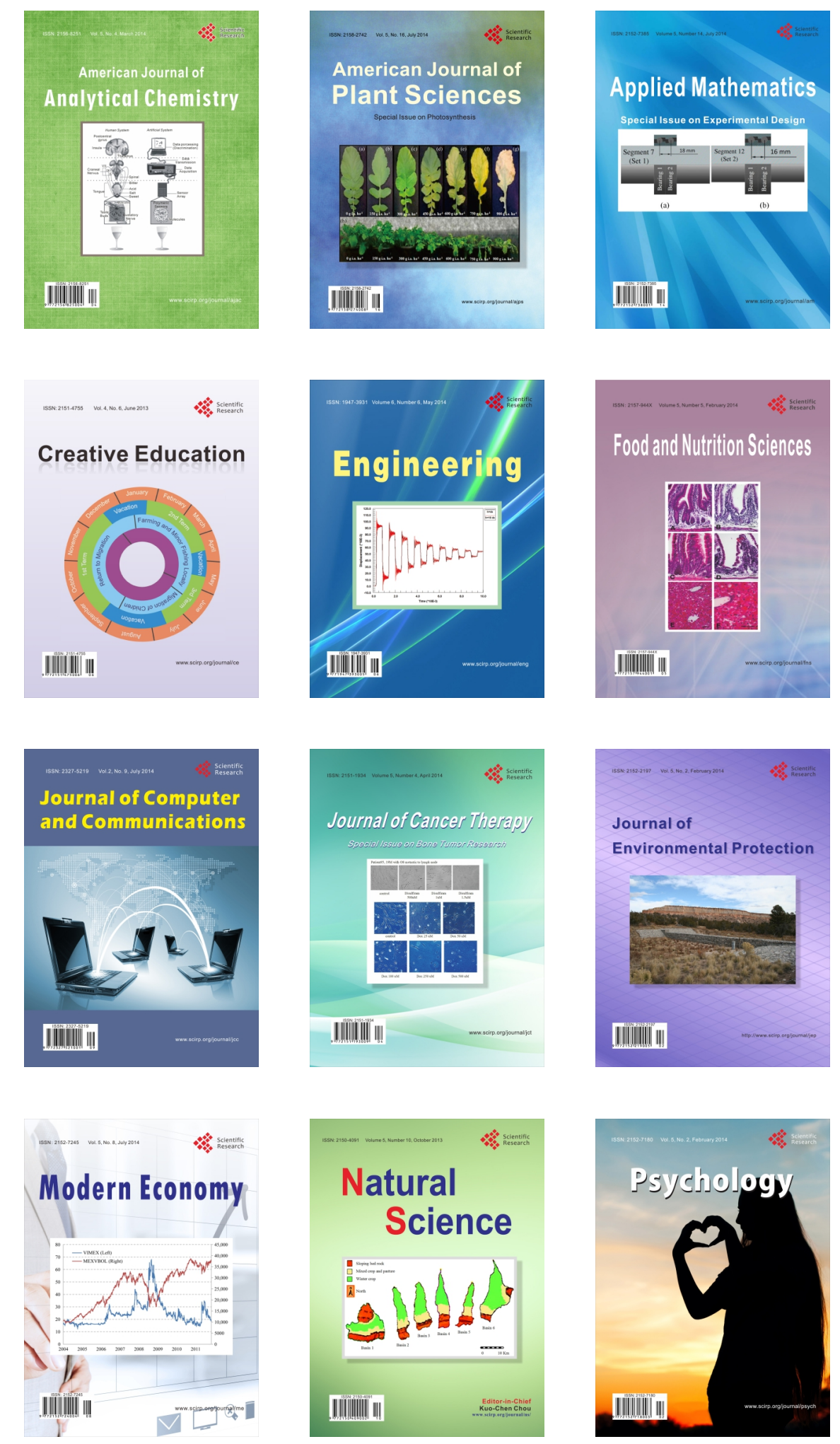